\title{
Physical Test Report to Drop Test of a 9975 Radioactive Material Shipping Packaging
}

by

P. S. Blanton

Westinghouse Savannah River Company

Savannah River Site

Aiken, South Carolina 29808

DOE Contract No. DE-AC09-96SR18500

This paper was prepared in connection with work done under the above contract number with the U. S. Department of Energy. By acceptance of this paper, the publisher and/or recipient acknowledges the U. S. Government's right to retain a nonexclusive, royalty-free license in and to any copyright covering this paper, along with the right to reproduce and to authorize others to reproduce all or part of the copyrighted paper. 


\section{DISCLAIMER}

This report was prepared as an account of work sponsored by an agency of the United States Government. Neither the United States Government nor any agency thereof, nor any of their employees, makes any warranty, express or implied, or assumes any legal liability or responsibility for the accuracy, completeness, or usefulness of any information, apparatus, product, or process disclosed, or represents that its use would not infringe privately owned rights. Reference herein to any specific commercial product, process, or service by trade name, trademark, manufacturer, or otherwise does not necessarily constitute or imply its endorsement, recommendation, or favoring by the United States Government or any agency thereof. The views and opinions of authors expressed herein do not necessarily state or reflect those of the United States Government or any agency thereof.

This report has been reproduced directly from the best available copy.

Available to DOE and DOE contractors from the Office of Scientific and Technical Information, P. O. Box 62, Oak Ridge, TN 37831; prices available from (423) 576-8401.

Available to the public from the National Technical Information Service, U. S. Department of Commerce, 5285 Port Royal Road, Springfield, VA 22161. 


\section{DISCLAIMER}

Portions of this document may be illegible electronic image products. Images are produced from the best available original document. 
Keywords:

Shipping Packaging

Drop Tests

Certification

Retention Permanent

PHYSICAL TEST REPORT FOR DROP TEST

OF A 9975 RADIOACTIVE MATERIAL SHIPPING PACKAGING (U)

\section{P.S. BLANTON}

OCTOBER 1997

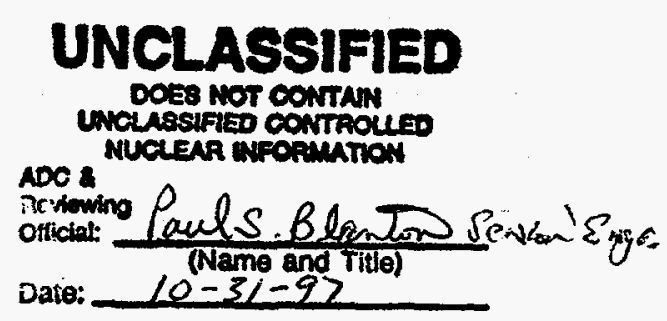

SRTC SAVANNAH RIVER TECHNOLOGY CENTER, AIKEN, SC 29808

Westinghouse Savannah River Company

Prepared for the U.S. Department of Energy under Contract DE-AC09-96SR18500 
SRTC/ Packaging and Transportation Group

WSRC-RP-97-00944

PROJECT: $\quad 9975$ SHIPINNG PACKAGING CERTIFICATION

DOCUMENT: WSRC-RP-17-00944

TITLE: $\quad$ PHYSICAL TEST REPORT FOR DROP TEST OF A 9975 RADIOACTIVE MATERIAL SHIPPING PACKAGING (U)

APPROVALS

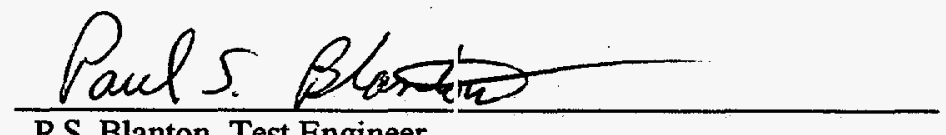

P.S. Blanton, Test Engineer Packaging and Transportation

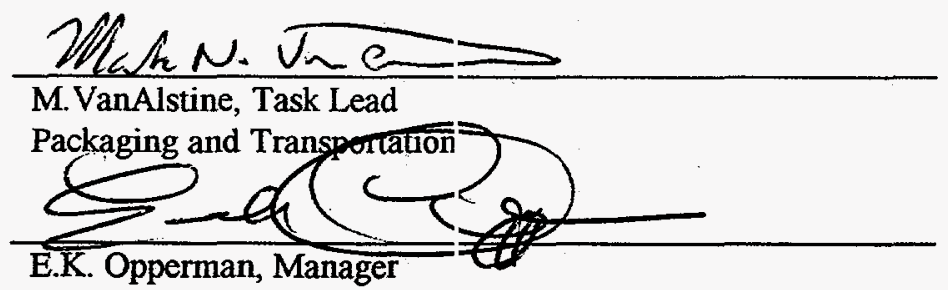

Packaging and Transportation

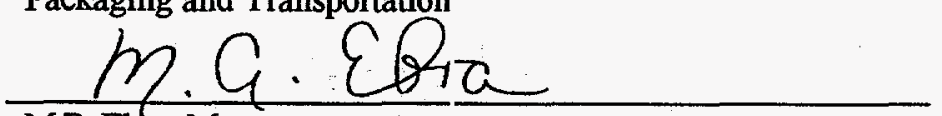

MR EboLa, Manager

Engineering Development
DATE $10-3 /-97$

DATE $11 / 5 / 97$

DATE $14(6 / 94$

Date? poo??

Page ii 


\section{EXECUTIVE SUMMARY}

Drop testing of the 9975 radioactive material shipping package with simulated payloads was conducted to evaluate the response of the drum lid closure to the effects of a 30 foot drop followed by 40 -inch puncture pin drop. The shipping packages were assembled per design drawings except that contents within the containment vessels were simulated using a solid steel bar and lead equivalent in weight to the calculated maximum content weight.

The package with its simulated contents was subjected to two drop tests. The first test, a 30 foot drop onto an unyielding surface, was designed to weaken the drum lid closure lug. The package was turned upside down and oriented at an angle between 25 and 30 degrees from horizontal. It was then rotated slightly to maximize deformation around the closure lug while still maintaining the extension of the lugs from the package surface to allow maximum impact advantage for the subsequent 40 -inch puncture pin drop.

The second test was a 40-inch drop onto 6-inch diameter, 40-inch long puncture pin. The test was designed to deliver the greatest impact to the protruding drum closure lug(s) in an attempt to disengage the lid. The package was held in an upright position with a slight 10 degree vertical angle.

The 9975 package performed well. Though the package sustained significant deformation from the $30-$ foot drop; there was no evidence of lid removal. No significant damage was incurred due to the 40 -inch puncture pin drop. 


\section{TABLE OF CONTENTS}

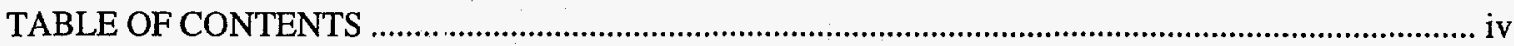

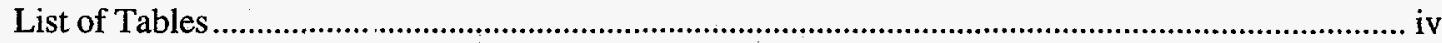

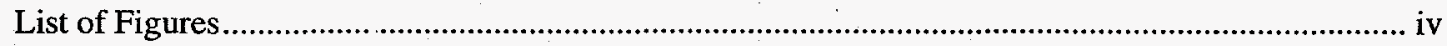

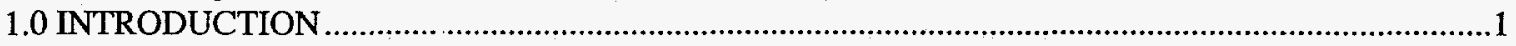

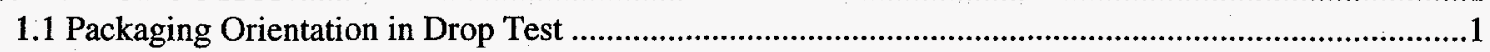

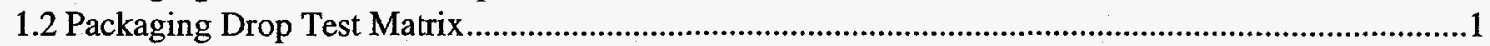

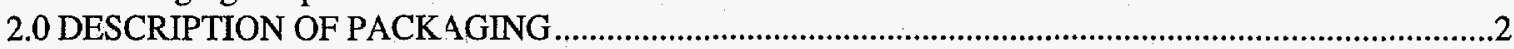

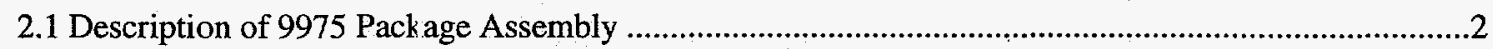

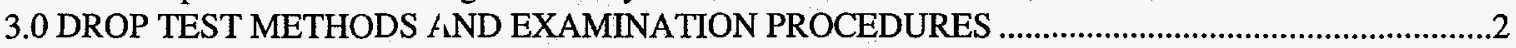

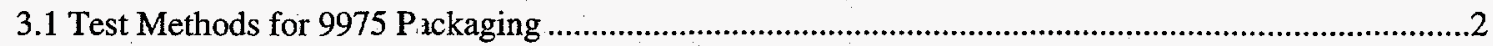

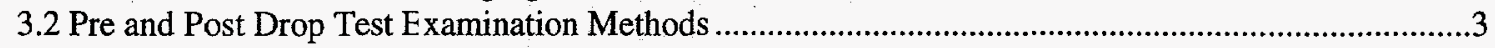

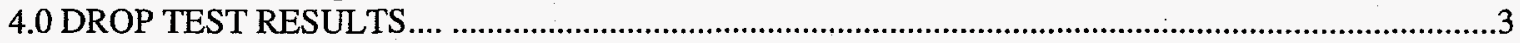

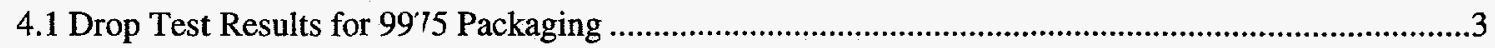

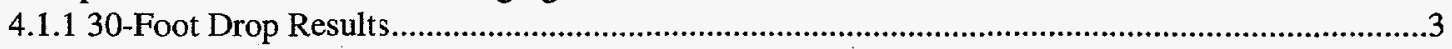

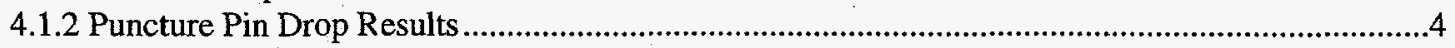

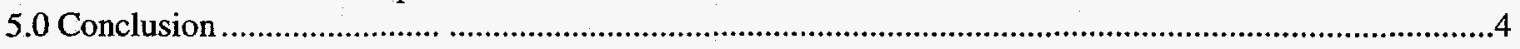

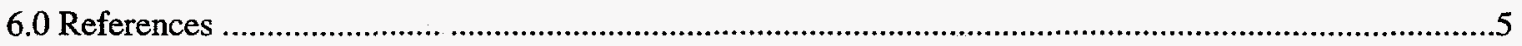

\section{LIST OF TABLES}

Table 1: 9975 Package Drop Tests ${ }^{[1]}$

Table 2: 9975 Packaging Assembly Checklist...............................................................................................

Table 3: 9975 and 9974 40-Inch Puncture Pin Lug Displacement Results ..................................................18

Table 4: 9975 and 9974 40-Inch Puncture Pin -Pin Displacement Comparison ............................................19

\section{LIST OF FIGURES}

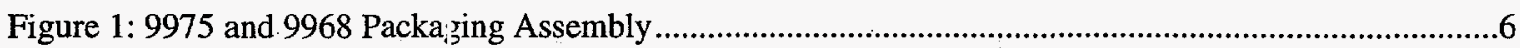

Figure 2: 9975 30-Foot and 40-inch Puncture Pin Test Orientations..............................................................8

Figure 3: 9975 30-Foot and 40-inch Package Orientations Before Drops .................................................

Figure 4: Photographs of the 9575 Package Following the 30-Foot Drop...............................................10

Figure 5: Post 30-Foot Drop Photographs of the 9975 Package ................................................................11

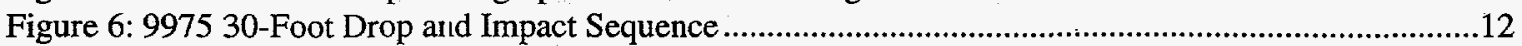

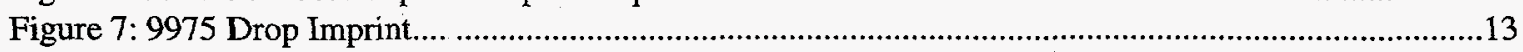

Figure 8: Drum Deformation following 40-inch Drop...............................................................................14

Figure 9: Post 40-Inch Puncture Pin Drop Photographs ..............................................................................15

Figure 10: Post 9975 40-Inch Puncture Pin Drop Photographs (Closure lug close-ups) ................................16

Figure 11: 9975 40-Inch Punctı re Pin Lug Displacement Measurements ......................................................17 


\subsection{INTRODUCTION}

This report presents the drop test results for the 9975 radioactive material shipping package being dropped 30 feet onto a unyielding surface followed by a 40-inch puncture pin drop. The purpose of these drops was to show that the package lid would remain attached to the drum. The 30-foot drop was designed to weaken the lid closure lug while still maintaining maximum extension of the lugs from the drum surface. This was accomplished by angling the drum approximately 30 degrees from horizontal in an inverted position. In this position, the drum was rotated slightly so as not to embed the closure lugs into the drum as a result of the 30-foot drop. It was determined that this orientation would maximize deformation to the closure ring around the closure lug while still maintaining the extension of the lugs from the package surface. The second drop was from 40 inches above a 40 -inch tall 6 -inch diameter puncture pin. The package was angled 10 degrees from vertical and aligned over the puncture pin to solidly hit the drum lug(s) in an attempt to disengage the lid when dropped.

Tests were performed in response to DOE EM-76 review Q5 inquires that questioned the capability of the 9975 drum lid to remain in place under this test sequence. Two packages were dropped utilizing this sequence, a 9974 and 9975 . Test results for the 9974 package are reported in WSRC-RP-97-00945. A series of 40-inch puncture pin tests were also performed on undamaged 9975 and 9974 packages independent of the 30-foot drop.

\subsection{Packaging Orientation in Drop Test}

The response of the 9975 package was evaluated after each of the following drop tests:

Table 1: 9975 Package Drop Tests ${ }^{[1]}$

\begin{tabular}{|l|l|l|}
\hline Packaging Type & Procedure Designation & Drop Test Orientation \\
\hline \hline $9975^{(\text {a) }}$ & F9-734 & $\begin{array}{l}\text { l0-foot drop up-side down; } \\
\text { package tilted 25-30 degrees from } \\
\text { horizontal. Package impact on } \\
\text { drum closure ring. }\end{array}$ \\
\hline 9975 & FP-734 & $\begin{array}{l}\text { 40-inch puncture pin drip, drum } \\
\text { right-side up: tilted 10 degrees } \\
\text { from vertical. Package impact on } \\
\text { drum closure lug(s) }\end{array}$ \\
\hline
\end{tabular}

Note:

(a) Reference WSRC-RP-97-00445 for 9974 package drop test results.

\subsection{Packaging Drop Test Matrix}

The drops described in this report are two of a series of four tests that were performed for 9975 and 9974 packages conducted in the period between October 9, 1997 and October 22, 1997 for the purpose of responding to Q5 certification questions for the 9972-9975 family of shipping packages. This report only documents the two drop tests performed on the 9975 package. 


\subsection{DESCRIPTION OF PACKAGING}

The 9975 package tested was fabricated and assembled as closely as possible in accordance with the appropriate design drawings ${ }^{[2-3}$, with some changes as noted below.

\subsection{Description of 997:; Package Assembly}

Because a prototype 9975 package was unavailable, the 9968 package, a package very similar in design, was used for testing purposes.

Table 2 and Figure 1 compare the 9975 and 9968 package assemblies and describes the tested package configuration. The primary difference between the 9968 and 9975 packages is the shielding configuration. The aggregate weight of each package is the same including the shielding. However the shielding geometry is slightly different as illustrated by Figures 1 . Table 2 lists the 9968 assembly configuration used for these drop tests.

The gross package weight used for these tests was $404 \mathrm{lbs}$. With the exception of the physical difference in shielding, lack of a few inner component retainer bolts and one honeycomb spacer and the drum air shield the tested package and 9975 paskage are the same.

The calculated content weight was simulated with a $44.4 \mathrm{lb}$. solid round bar of steel. The simulated content was firmly packed within a 9975 primary containment vessel.

The drum lid was closed in accurdance with established procedure as referenced in the Safety Analysis Report - Packages 9968, 9972-9975 Packages. ${ }^{[4]}$ The lid closure ring was repeatedly hit with a rubber mallet while the lug bolt was torqued to the required $50 \mathrm{ft}-\mathrm{lb}$.

\subsection{DROP TEST METHODS AND EXAMINATION PROCEDURES}

The 9975 package was subjected to drop tests designed to disengage the drum lid from the body of the drum. The drop test conditions and orientations are specified in test procedures. ${ }^{[1]}$

\subsection{Test Methods for 9975 Packaging}

The 9975 package was inclined at approximately 30 degrees from horizontal in an inverted position and dropped 30 feet onto a rigid drcp pad. The purpose of the test was to weaken the drum ring and the drum ring closure lug assembly prior to a puncture pin drop. Figure $2 \mathrm{~A}$ graphically illustrates the 30 -foot drop orientation. Following the 30 -foot drop the damaged package was dropped from a position 40 inches above the surface of a 6 -inch diameter 40 -inch long puncture pin as graphically illustrated in Figure $2 \mathrm{~B}$. The drop was designed to impact the weakened drum closure lugs from below in an attempt to fail the lid. Figures $3 \mathrm{~A}$ and 3B are photographs of the 9975 package orientation prior to each drop. Figure 3A shows the 9975 package positioned just above the drop pad before it is hoisted up 30 feet and dropped. Figure $3 \mathrm{~B}$ presents two orientation photographs of the 40 -inch puncture pin test. The top photo was taken to show the impact position of the $\operatorname{lug}(\mathrm{s})$. In this ploto the desired drum orientations have been set. The bottom photograph shows two plumb lines that were used to align the package and puncture pin for the test. 


\subsection{Pre- and Post-Drop Test Examination Methods}

The results of the drop tests were documented using dimensional measurements and photography of the external condition of the Package. Video recordings were taken to document the actual drop impact and Packaging response. Pre- and post-drop examination procedures are specified in test procedure. ${ }^{[1]}$

\subsection{DROP TEST RESULTS}

The physical damage which occurred to the external components of the shipping package as a result of the drops is reported below. Internal package damage was not evaluated.

\subsection{Drop Test Results for 9975 Packaging}

The 9975 package performed well through both tests. After the 30-foot drop, both drum and drum closure ring sustained significant deformation very close to the drum closure lugs, however, the closure lid remained secured to the package. The sequential 40 -inch puncture drop did little damage to the drums closure lugs and the lid remained secured to the package.

\subsubsection{0-Foot Drop Results}

Figure 4 presents photographs of the package following the 30-foot drop. The package impacted the pad as planned. Upon impact the drum rotated about the impacted drum chime, slapping down on the steel pad. As the drum rebounded, it kicked backwards while simultaneously rotating bottom up through an angle of approximately 40 degrees before striking the steel pad again in nearly the same orientation but 18 inches from its original impact area. On the second strike the drum again rotated about the top chime and slapped down. Following the second slap, the drum skidded backwards and came to a rest 11 inches back from the second impact area. In all, the drum traveled 29 inches following its initial impact on to the steel pad. Refer to Figure 6 for an illustration of the impact sequence and Figure 7 for a photograph of the imprint left on the pad following the drop.

The 30-foot impact produced a 9-1/2 inch wide flattened area along the drum edge as seen in Figure 4 and Figure 7. The flattened area, in the shape of a half ellipse, extends approximately $8-1 / 4$ inches down the side of the drum. Close to the top of the drum and symmetrical about the ellipse centerline, the drum is sunken approximately 1.2 inches from buckling under the initial impact. The flats along the length of the drum were produced by the subsequent drum slaps against the steel slab. The slap-down impacts also flattened that drums reinforcing wall hoops as can also be seen in Figure 4. Again in Figure 5 the distortion at the top of the drum stops between the drum closure lugs.

The 30-foot drop caused the threaded lug and bolt side of the lugs to slightly rotate upwards, 0.32 inches and 0.07 inches, respectively. The direction the lugs rotated optimally positioned them for the subsequent 40-inch puncture pin drop. Figure 5 presents the before and after conditions of the lugs following the 30-foot drop. Each lug experienced very little rotational movement, however, the left lug bent outward approximately 30 degrees as illustrated. The minimal upward movement of the lugs appears to be somewhat proportional to the distance between the drum lid and the ring extensions ${ }^{[5]}$ which are attached to the drum closure ring above each lug. These extensions are welded in place and wrap over the edge of the drum. Figure 10 presents close up shots of these extensions. Because the physical distance between the bottom of the extensions and the top of the drum is small (on average 0.34 inches) the distance the extensions can travel due to an impact, except during the most direct hits, is limited. More direct impacts to the lugs tend to just embed them into the drum as shown by earlier testing. ${ }^{[6]}$ The extensions above the 
non-threaded lug and threaded ug moved 0.2 inches and 0.17 inches, respectively, as measured from the center of each extension to the id. Table 4 compares the lug and the ring extensions displacement changes following each drop. ${ }^{[1,7]}$

Following all drops the lug wel As and the ring extension welds showed no signs of damage. The bolt showed no signs of damage.

\subsubsection{Puncture Pin Drop Fiesults}

The 40-inch puncture pin drop est pioduced very little drum deformation compared to the 30-foot drop test. The deformation that did occur was located just around the closure lugs. Specifically, the only measurable deformation evident after the drop was the movement of the impacted non-threaded lug. The body of the drum received no damage from the drop. Video review of the impact does not indicate any potential lid failure.

The drum was oriented so that loth lugs would solidly strike the pin. When the magnetic drop release mechanism was activated the dium rotated slightly resulting in only the non-threaded lug solidly striking the 6-inch diameter pin. The threarled lug just nicked the rim of the pin as evidenced by the scared drop surface shown in Figure 8.

The measured permanent rotation of the non-threaded closure lug was approximately 0.45 inches, however, this measurement was difficult "o make because of the magnitude of preceding deformation from the 30 -foot drop.

Of more importance other than physical measurements which were made, is the general observation that the drum closure is not breached ard further, very little damage is done to the lug connection due the 40-inch puncture pin drop. This conclusion was reached based on observations from a series of 40-inch puncture pin drops that included - this drop, two earlier drops using the same 9975 package but not damaged by a 30-foot drop and two drops wi h a heavier 9974 drum also not damaged by a 30-foot drop. Figure 11 presents the method that was used to make lug displacement measurements on the 9975 and 9974 test packages. Table 3 presents the results of the lug displacement measurements that were made for the 9975 drop tests. ${ }^{[1,7]}$ Also included in Table 3, for comparison are the measurement results that were made for the 9974 puncture pin drops. For a more complete description of the 9974 drops reference report

WSRC-RP-97-00945.

\subsection{Conclusion}

Tests conducted on the 9975 package consisted of a 30 -foot free fall onto a rigid surface followed by a 40inch free fall onto a regulatory juncture pin. Results from the tests support a conclusion that the 9975 package lid will not be disenga;ed by this drop test sequence. Based on careful review of the data, i.e., dimensional measurements, video footage of drops, the test that has a much greater potential for disengaging the lid from the drum would be the angled 30-foot drop. The subsequent 40 -inch puncture pin test does not represent a failure mode for disengaging the lid from a 9975 package. 


\subsection{References}

1. Procedure for the 9974 or 9975 Shipping Package Drum Closure Sequential 30 Foot Drop and Puncture Tests, Procedure Number FP-734, Revision 0, October 1997. Westinghouse Savannah River Company. Job Folder \#22479, Subfolder “9965-9975 Round 5 Responses."

2. Drawing S5-2-13101, Revision 58, "9968 Shipping Package Assembly 35 Gal Drum Overpack W/Stretched Double Containment and Lead Shielding," Westinghouse Savannah River Company.

3. Drawing R-R1-F-0005, Revision 1, “9975 Packaging Assembly," Westinghouse Savannah River Company, Aiken, S.C.

4. Safety Analysis Report - Packages 9968, 9972-9975 Packages, WSRC-SA-7, Revision 3. Westinghouse Savannah River Company, Aiken, S.C.

5. Drawing R-R2-F-0006, Revision 2, “9972 Series Packaging Drum Subassemblies (U)," Westinghouse Savannah River Company, Aiken, S.C.

6. Drop Test Report for 9974C and 9974D Radioactive Material Shipping Packaging (U), E.J. Majzlik, September 1994. WSRC-RP-94-724, Westinghouse Savannah River Company, Aiken, S.C.

7. Procedure for the 9974 and 9975 Shipping Package Drum Closure Puncture Tests, Procedure Number FP-731, Revision 0, October 1997. Westinghouse Savannah River Company. Job Folder \#22479, Subfolder "9965-9975 Round 5 Responses." 

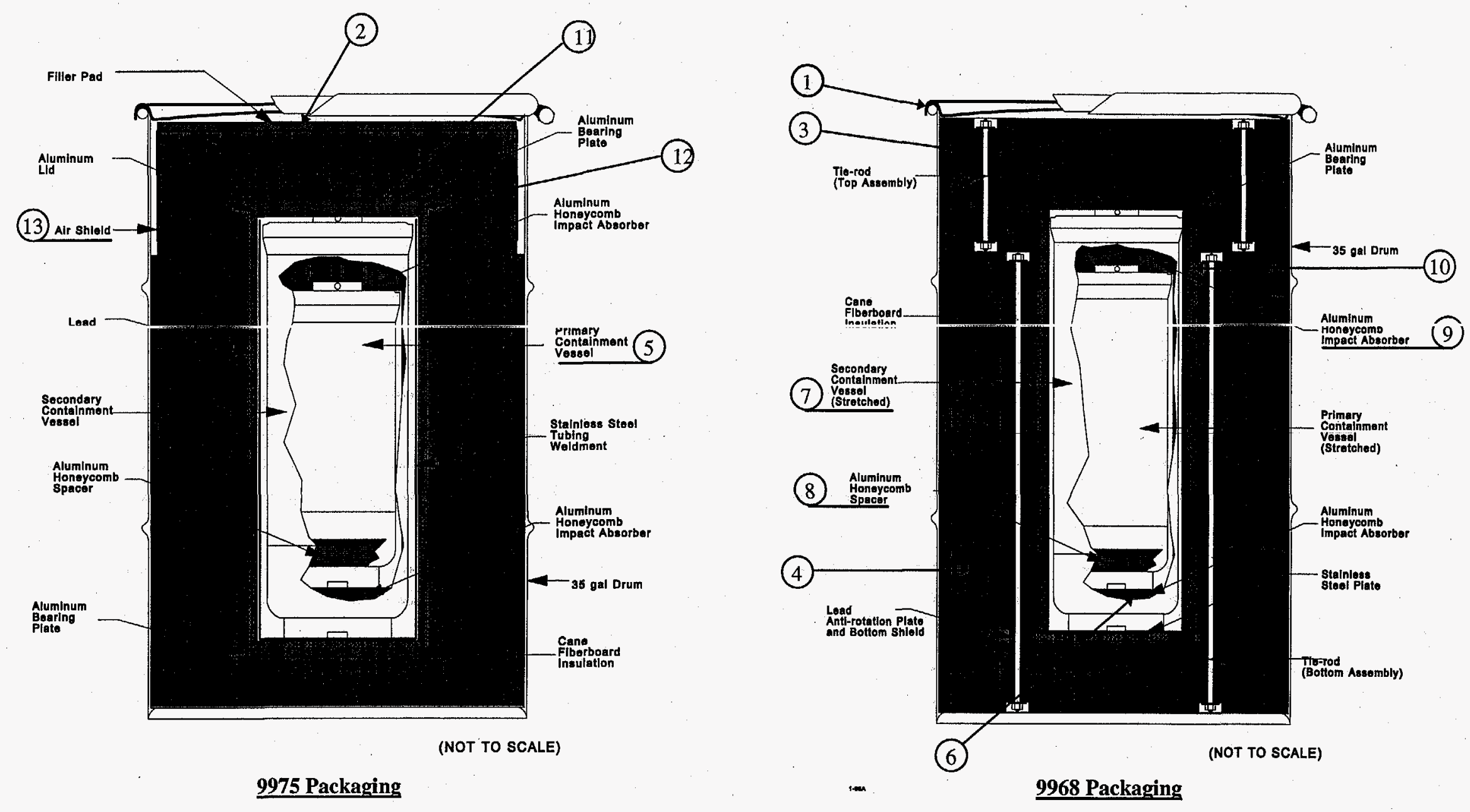

Figure 1: 9975 and 9968 Packaging Assembly 
Table 2: 9975 Packaging Assembly Checklist

\begin{tabular}{|c|c|c|}
\hline \multicolumn{3}{|c|}{9975 Tested Package Assembly Description } \\
\hline $\begin{array}{l}\text { Item* } \\
\text { Number }\end{array}$ & Item Description & Checked if correct assembly item is used. If not, a description of the substitute item is provided. \\
\hline 1 & 9975 Drum Assembly & 1.9968 Packaging Property ID\# 00359856 \\
\hline 2 & Firemaster encapsulated blanket & 2. Not included; no substitute. \\
\hline 3 & Insulation top subassembly & $3 . \checkmark$ \\
\hline 4 & Insulation bottom subassembly & $4 . \checkmark$ \\
\hline 5 & Primary Containment Vessel (PCV) & $5 . \checkmark$ \\
\hline 6 & PCV bottom spacer & $6 . \checkmark$ \\
\hline 7 & Secondary Containment Vessel (SCV) & $7 . \checkmark$ \\
\hline 8 & SCV bottom spacer & $8 . \checkmark$ \\
\hline 9 & SCV top Spacer & 9. Not included; space used to add extra weight to equal gross calculated package weight. \\
\hline 10 & Shielding body subassembly & 10.6 \\
\hline 11 & Shielding lid subassembly & $11 . \checkmark$ \\
\hline 12 & $1 / 2 "$ hex head shielding lid bolts & 12. Not included; no substitute \\
\hline 13 & Air shield & 13. Not included; no substitute \\
\hline
\end{tabular}

*Refer to Figure 1 for item number designations. 

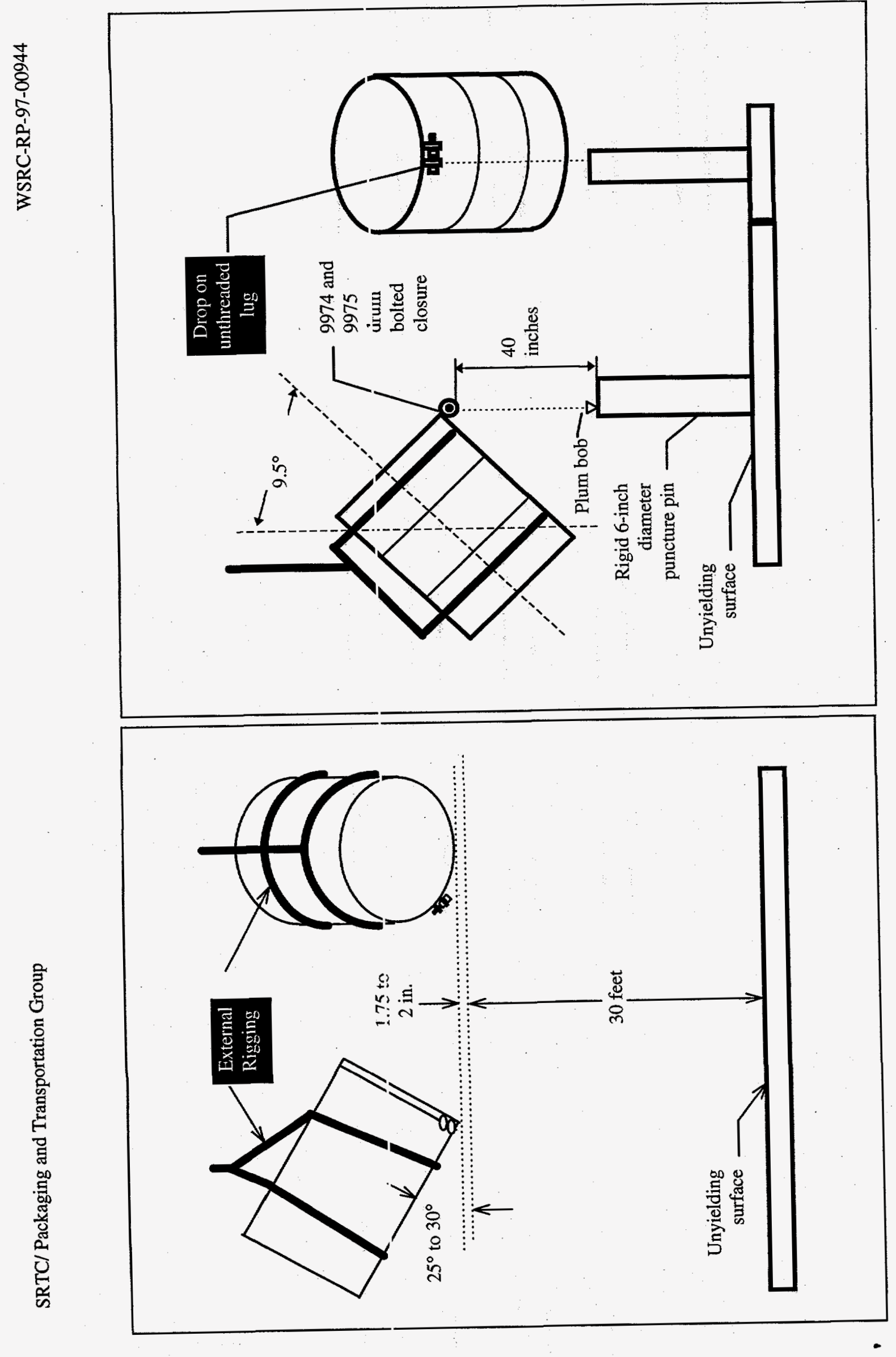

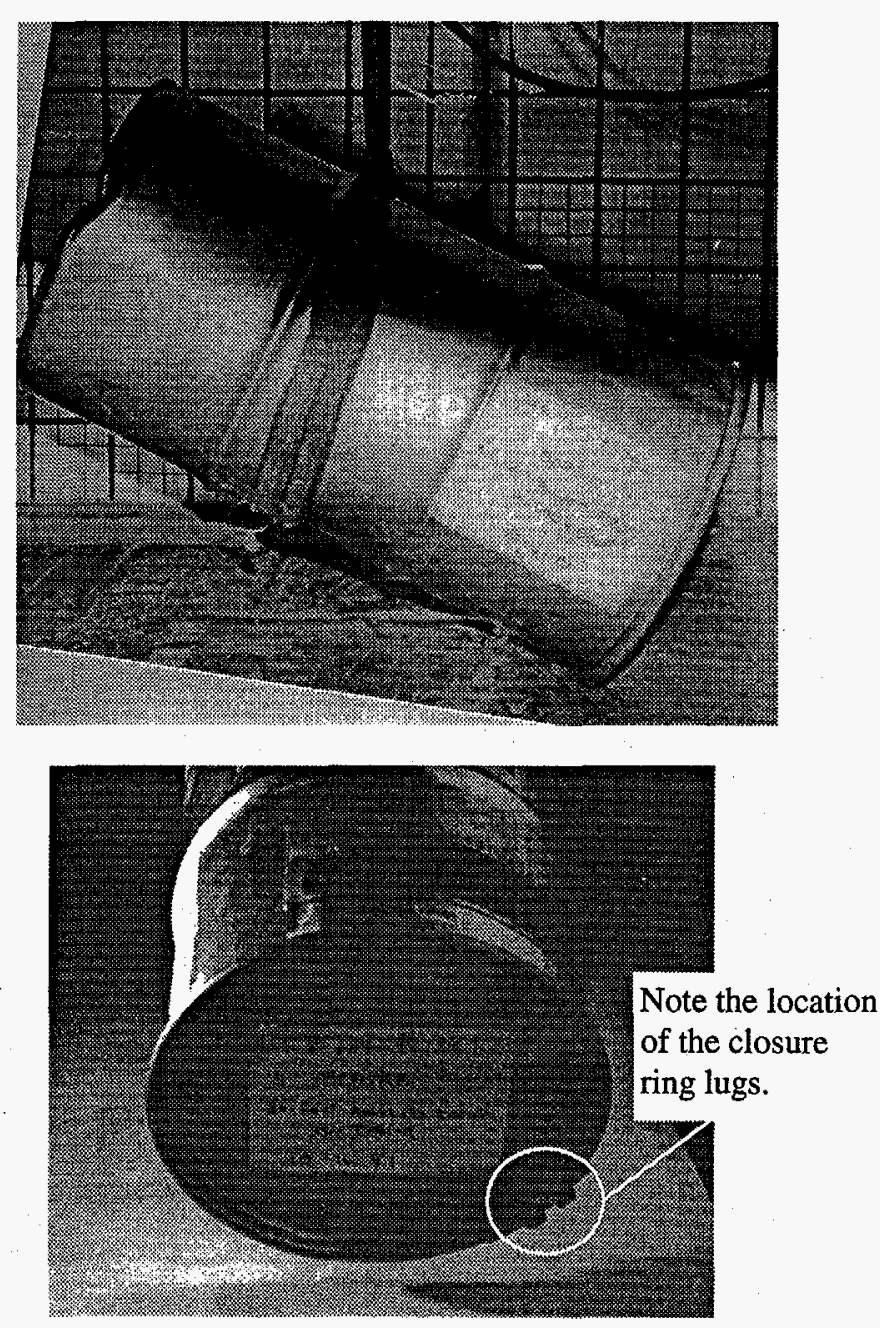

FIGURE 3A - 9975 Package Orientation Before 30-Foot Drop

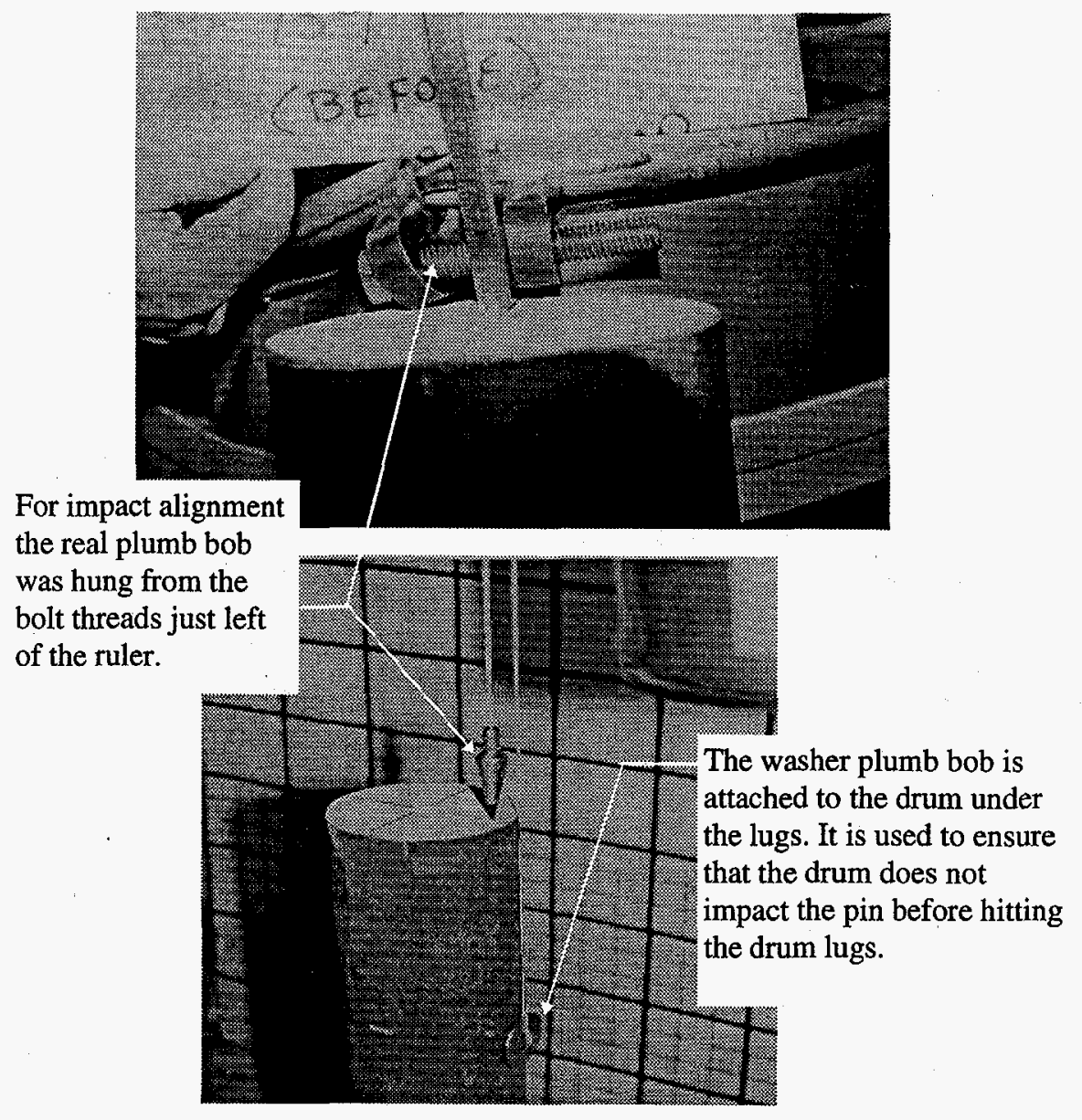

FIGURE 3B - 9975 Package Orientation Before 40-inch Pin Drop

Figure 3: 9975 30-Foot and 40-inch Package Orientations Before Drops 

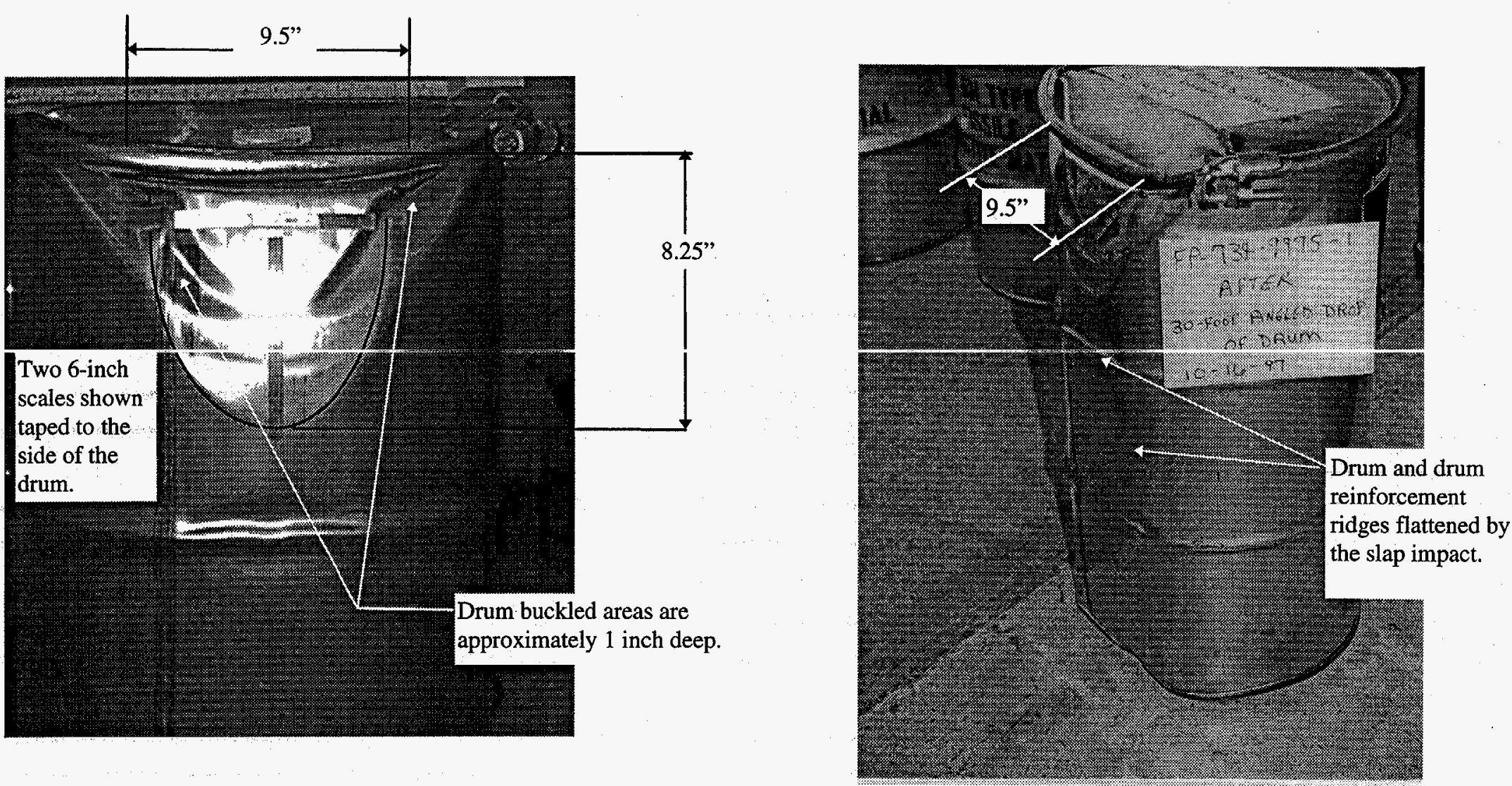

Figure 4: Photographs of the 9975 Package Following the 30-Foot Drop 

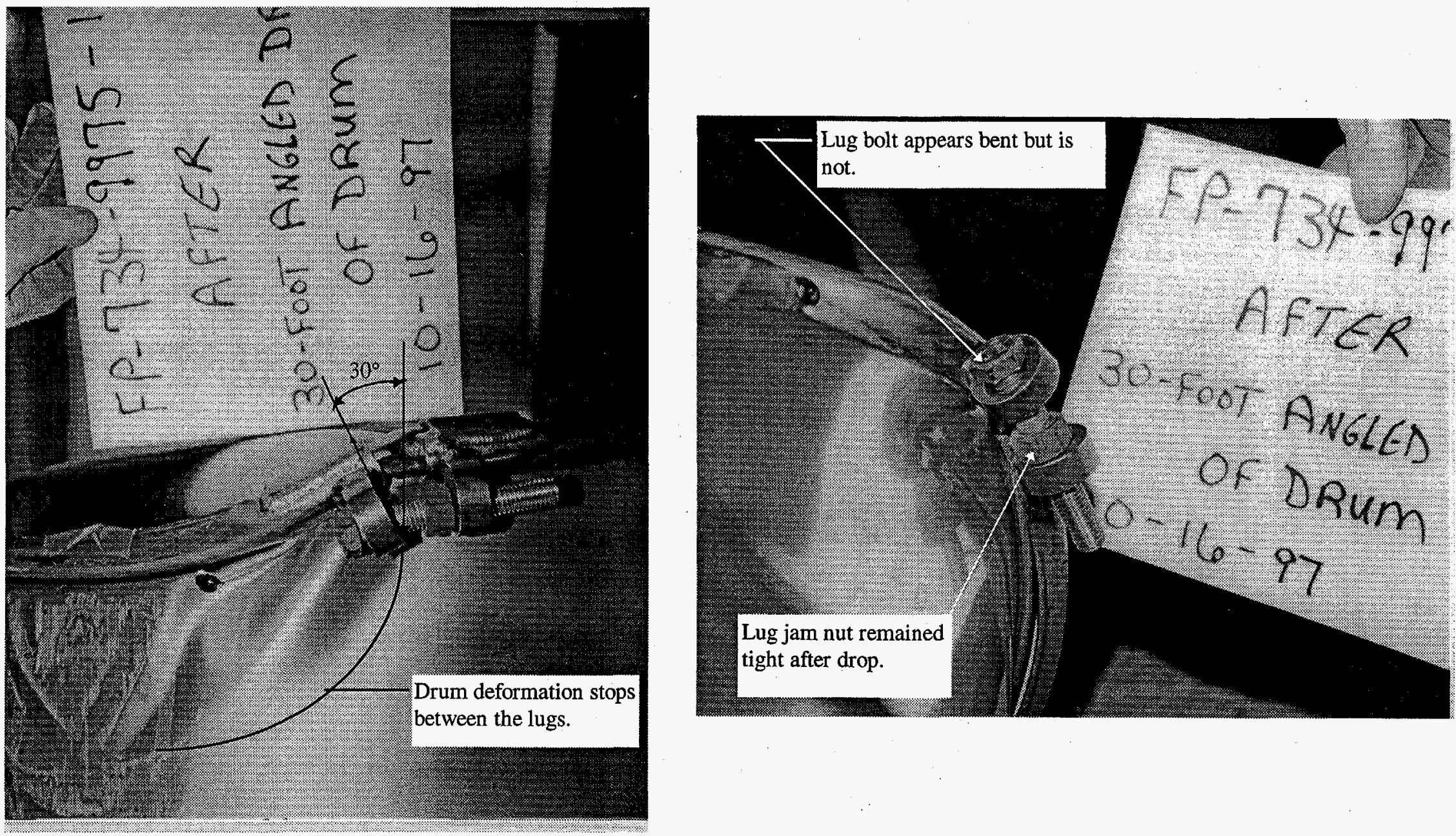

Figure 5: Post 30-Foot Drop Photographs of the 9975 Package 
4
8
8
0
5
0
0
0
0
0
0
0
3

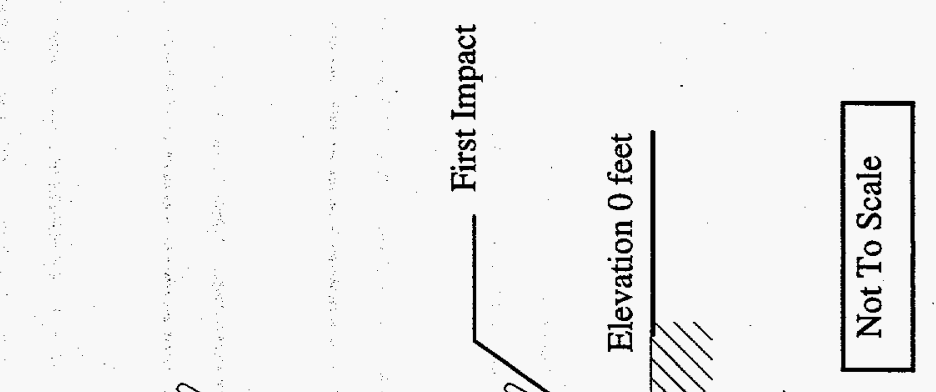

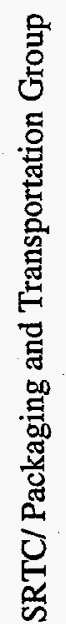
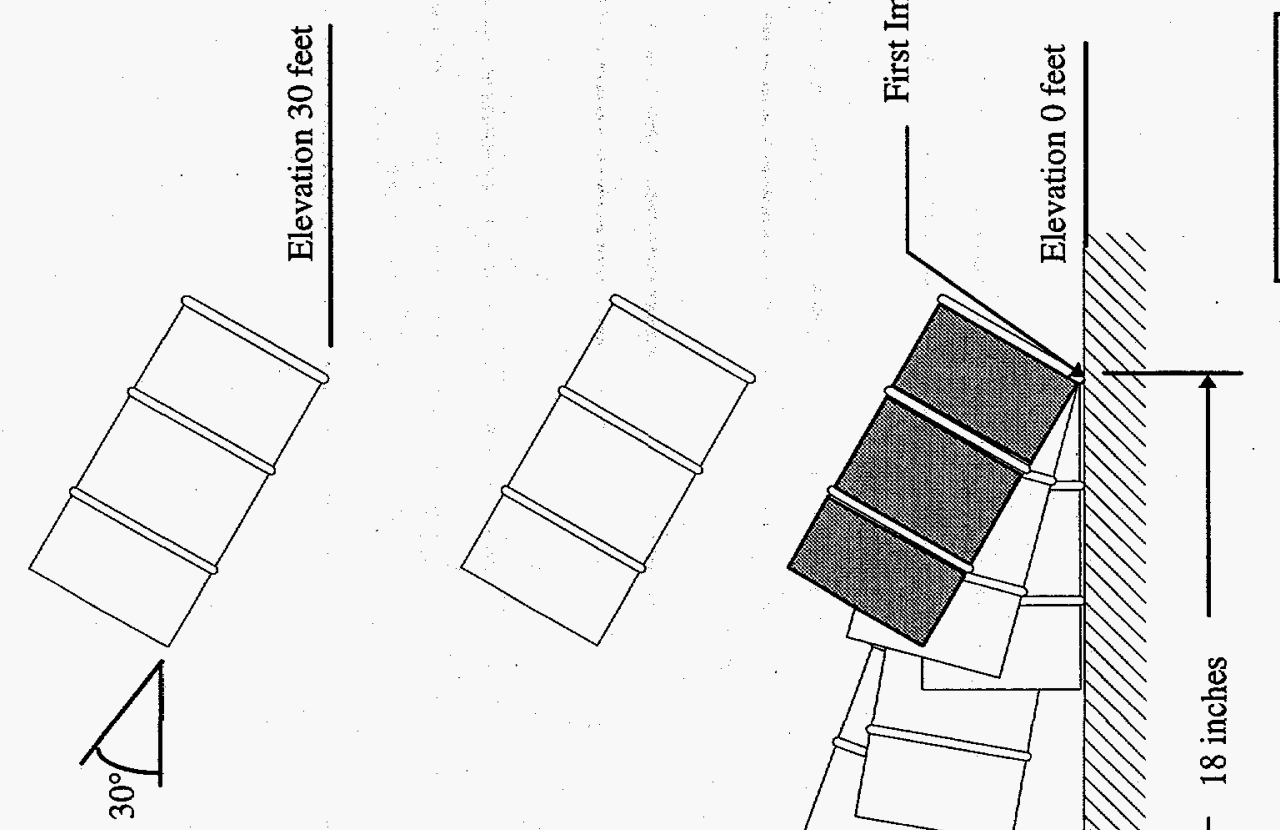

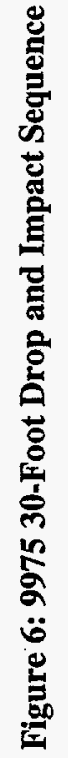

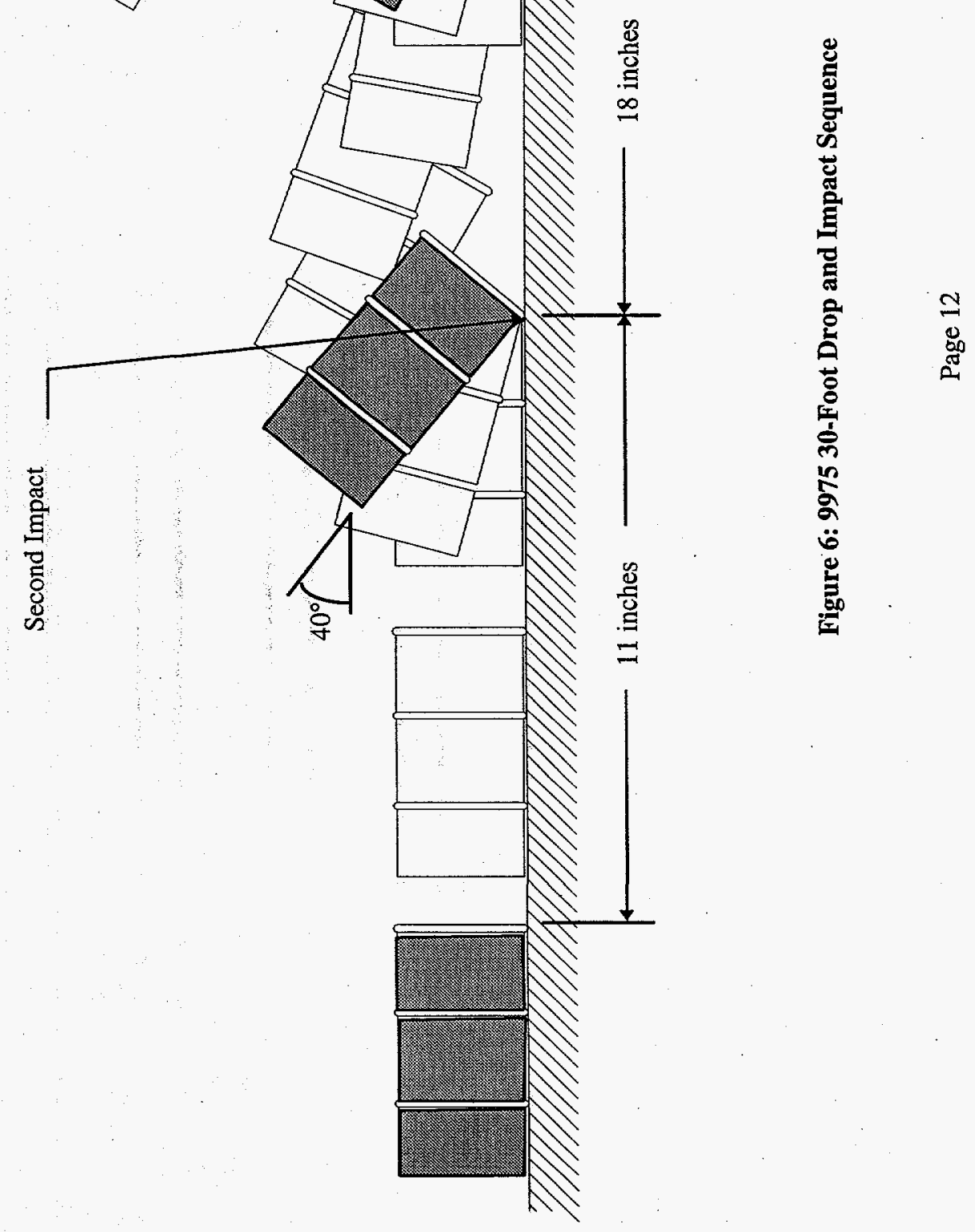




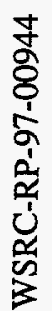
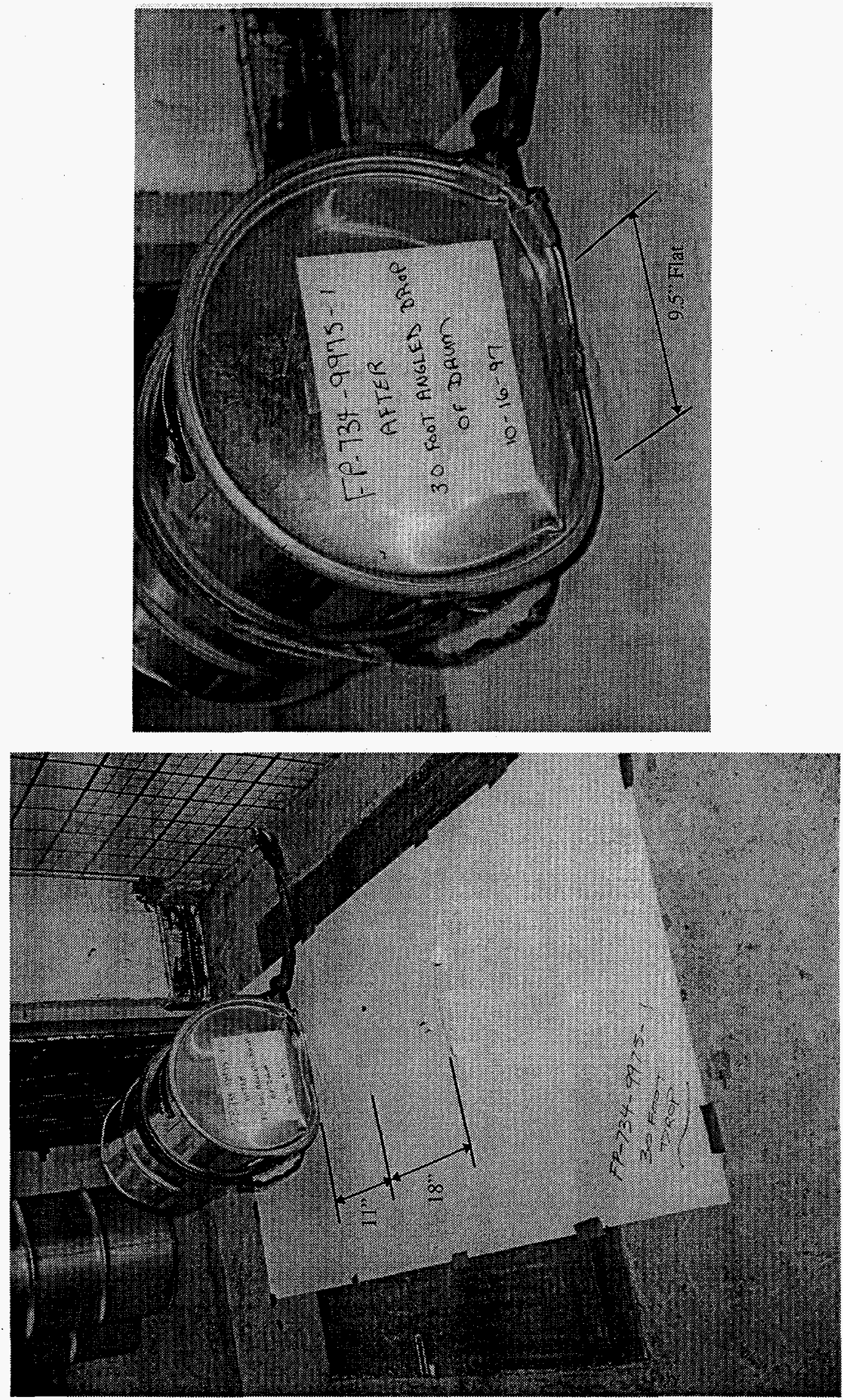

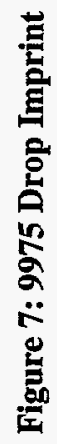

苛 

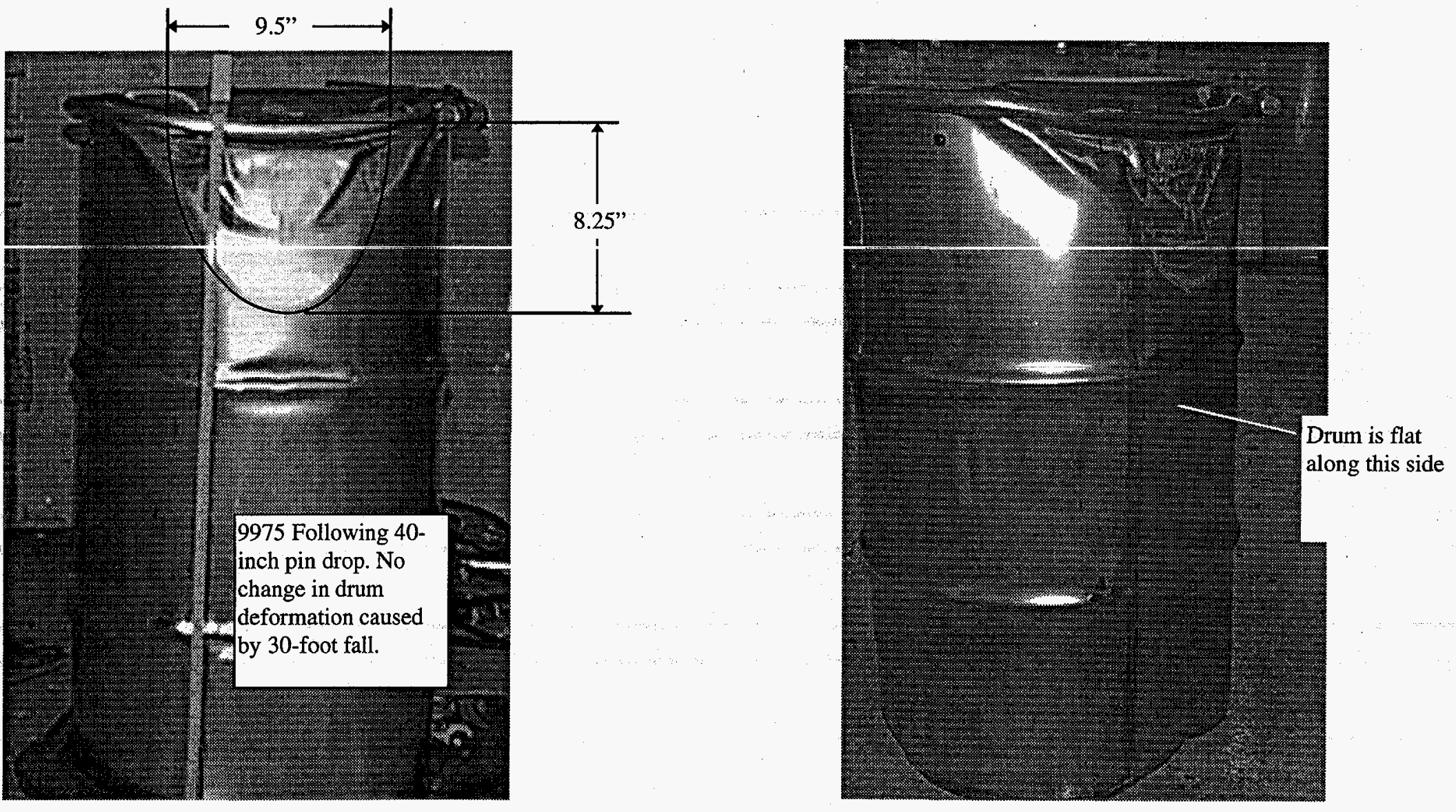

Figure 8: Drum Deformation following 40-inch Drop 


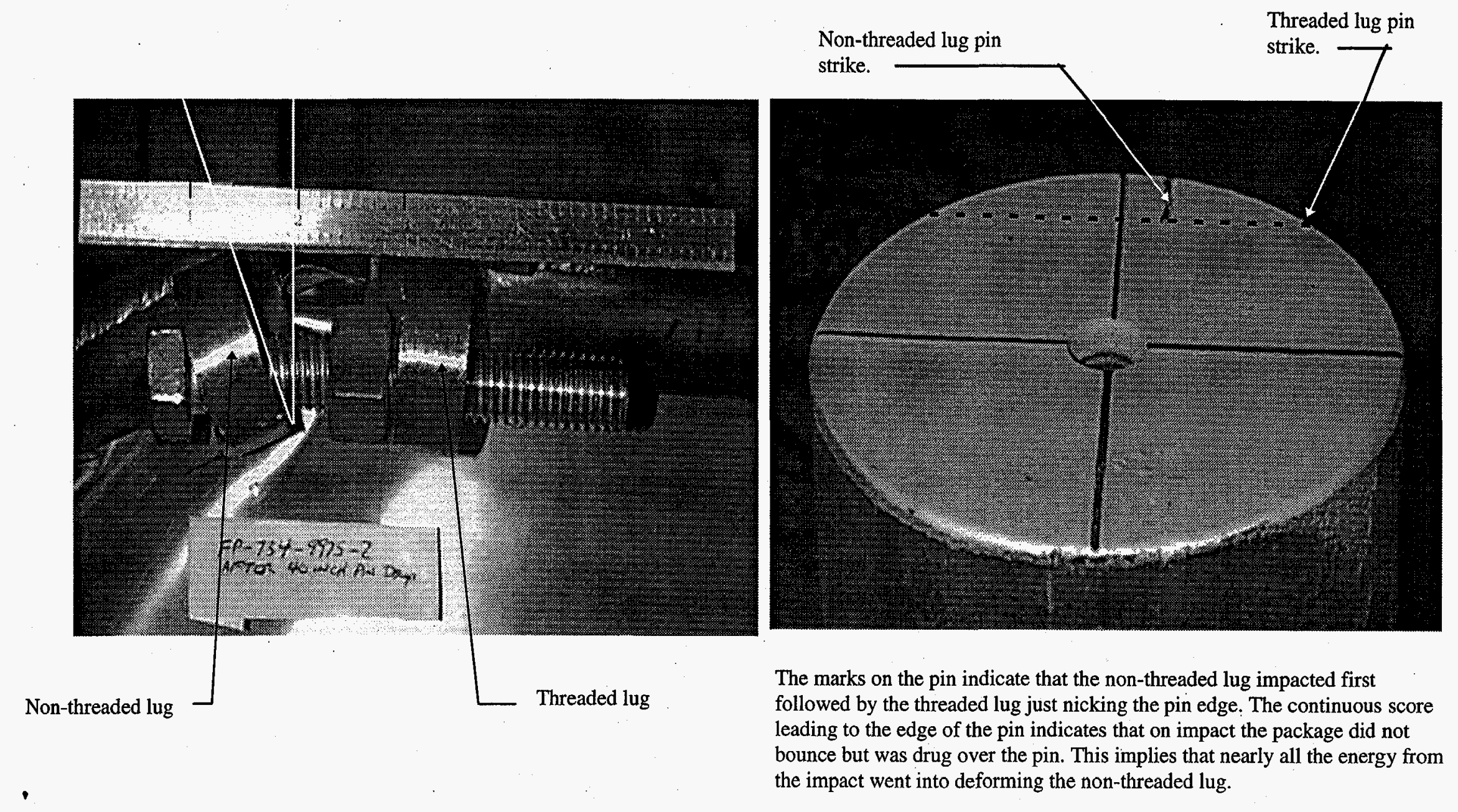

Figure 9: Post 40-Inch Puncture Pin Drop Photographs 

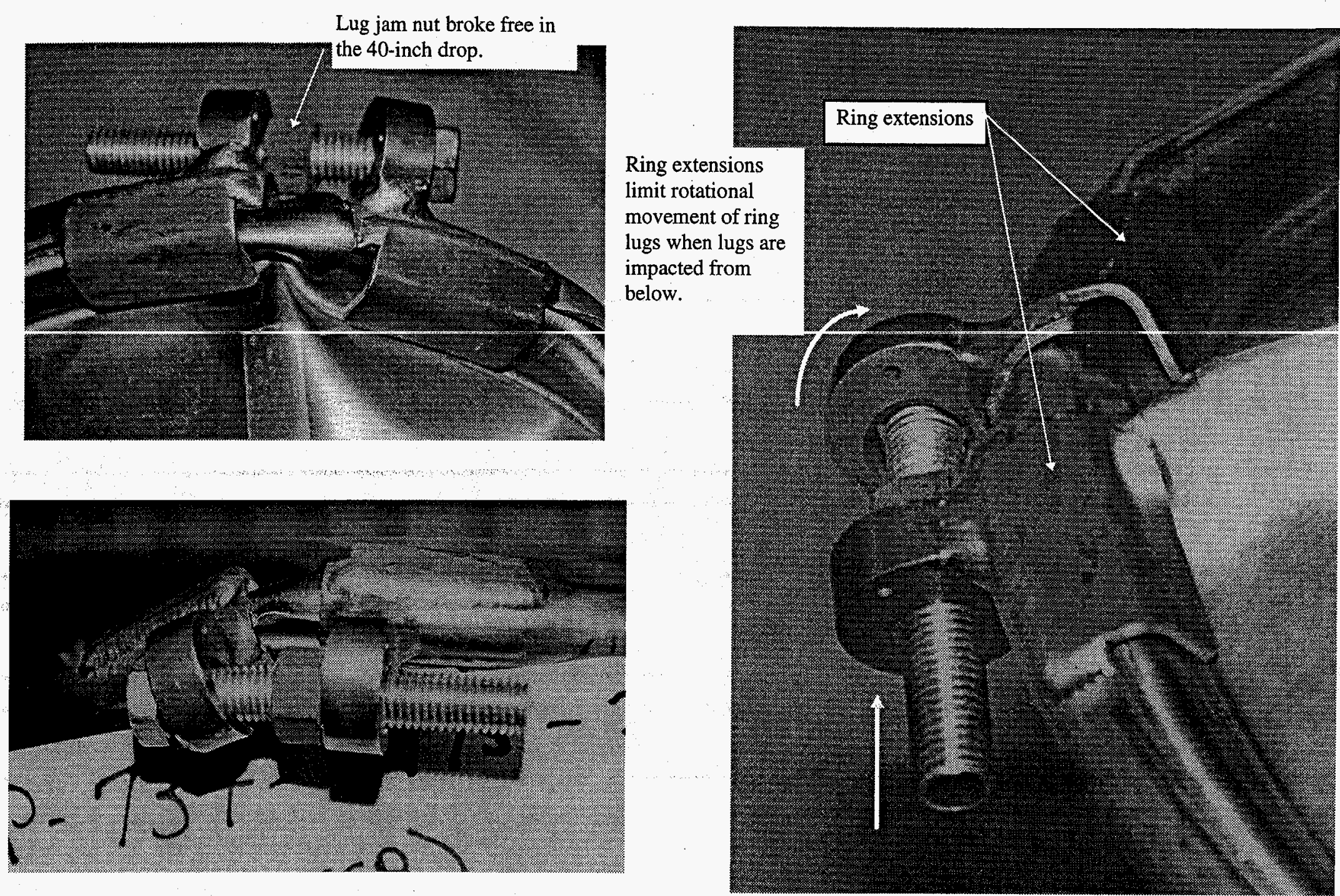

Figure 10: Post 9975 40-Inch Puncture Pin Drop Photographs (Closure lug close-ups) 


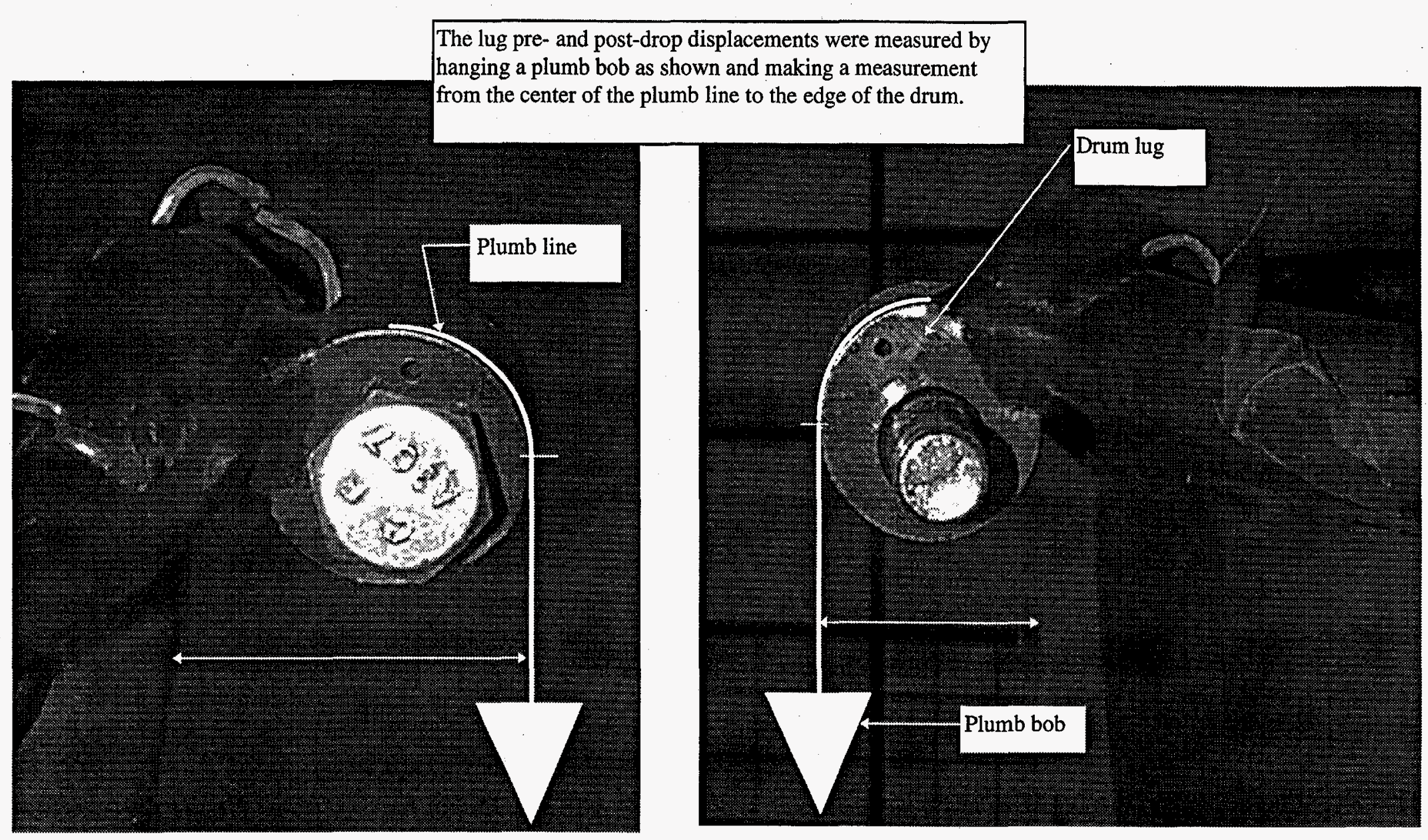

Lug Photographs are of the 9975 package , following the FP-734-9975-2 test.

Figure 11: 9975 40-Inch Puncture Pin Lug Displacement Measurements 
Table 3 : 9975 and 9974 40-Inch Puncture Pin Lug Displacement Results

\begin{tabular}{|c|c|c|c|c|c|}
\hline \multicolumn{6}{|c|}{ 40-Inch Puncture Pin Lug Displacement Results } \\
\hline \multirow{3}{*}{ Drop Test Number } & \multirow{3}{*}{ Lug Impact Description on Pin } & \multicolumn{4}{|c|}{ Lug Displacement } \\
\hline & & \multicolumn{2}{|c|}{ Threaded } & \multicolumn{2}{|c|}{ Non-Threaded } \\
\hline & & Before & After & Before & After \\
\hline & & & & & \\
\hline FP-731-9975-1 (a) & Solid hit by both ring lugs & (not measured) & 2.18 & 1.9 & 2.18 \\
\hline 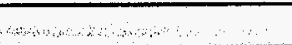 & 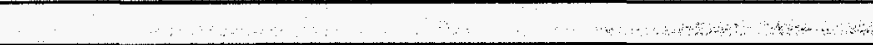 & 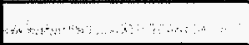 & & & $\ldots$ \\
\hline FP-731-9975-2 (a) & Solid hit on Non-threaded lug; partial hit on threaded lug & 1.75 & 2.15 & 1.83 & 2.10 \\
\hline FP-734-9975-2 ${ }^{(6)}$ & Solid hit on Non-threaded lug; slight contact by threaded lug & 2.1 & 2.45 & 1.9 & 2.35 \\
\hline 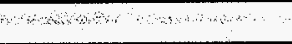 & 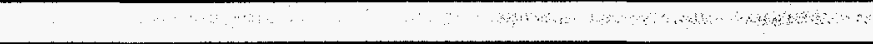 & 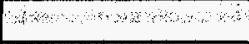 & & & s.m \\
\hline FP-731-9974-2 ${ }^{(\mathrm{a})}$ & Solid hit on Non-threaded lug; slight hit on threaded lug & 1.40 & 1.66 & 1.48 & 1.64 \\
\hline FP-731-9974-1 ${ }^{\text {(a) }}$ & Solid hit by both lugs & (not measured) & (not measured) & 1.10 & 1.63 \\
\hline
\end{tabular}

Notes:

(a) Package not subjected to 30 foot drop.

(b) This test was preceded by a 30 -foot drop test. 
Table 4: 9975 and 9974 40-Inch Puncture Pin -Pin Displacement Comparison

\begin{tabular}{|c|c|c|c|c|c|}
\hline \multicolumn{6}{|c|}{$\begin{array}{l}9975 \text { and } 9974 \\
\text { Lug - Ring Extension Displacement Comparison } \\
\text { Following 40-inch Puncture Pin Drop }\end{array}$} \\
\hline \multirow[t]{3}{*}{ Drop Test Number } & \multirow[t]{3}{*}{ Lug- Pin Impact Description } & \multirow{2}{*}{\multicolumn{2}{|c|}{$\begin{array}{l}\text { Lug - Extension D } \\
\text { Threaded Side } \\
\end{array}$}} & \multirow{2}{*}{\multicolumn{2}{|c|}{$\begin{array}{l}\text { ent Comparison } \\
\text { Non-Threaded Side }\end{array}$}} \\
\hline & & & & & \\
\hline & & Lug & Extension & Lug & Extension \\
\hline FP-731-9975-1 ${ }^{\text {(a) }}$ & Solid hit by both ring lugs & 0.28 (guess) & 0.27 & 0.28 & 0.20 \\
\hline FP-731-9975-2 ${ }^{(a)}$ & Solid hit on Non-threaded lug; partial hit on threaded lug & 0.4 & 0.25 & 0.27 & 0.24 \\
\hline FP-734-9975-2 ${ }^{(b)}$ & $\begin{array}{l}\text { Solid hit on Non-threaded lug; slight contact by threaded } \\
\text { lug }\end{array}$ & 0.35 & 0.02 & 0.45 & 0.1 \\
\hline FP-731-9974-2 ${ }^{(a)}$ & Solid hit on Non-threaded lug; slight hit on threaded lug & 0.26 & .265 & 0.16 & 0.2 \\
\hline FP-731-9974-1 ${ }^{(\mathrm{a})}$ & Solid hit by both lugs & 0.53 (guess) & 0.44 & 0.53 & 0.3 \\
\hline
\end{tabular}

Notes:

(a) Package not subjected to 30 foot drop.

(b) This test was preceded by a 30-foot drop test. 